\title{
Experiments and transient simulation on spring-loaded pressure relief valve under high temperature and high pressure steam conditions
}

\author{
Liu Yang ${ }^{1}$, Zhoujie Wang ${ }^{1,2}$, William Dempster ${ }^{3}$, Xinhai Yu ${ }^{1},{ }^{*}$, Shan-Tung Tu ${ }^{1}$ \\ ${ }^{1}$ Key Laboratory of Pressure Systems and Safety (MOE), School of Mechanical Engineering, East China \\ University of Science and Technology, Shanghai 200237, China \\ ${ }^{b}$ Shanghai Power Equipment Research Institute (SPERI), Shanghai 200240, China \\ 'Department of Mechanical and Aerospace Engineering, University of Strathclyde, Glasgow, United Kingdom
}

\begin{abstract}
A b stract
Reliable performances of high temperature and high pressure operating steam pressure relief valves (HTHP PRVs) are extremely important for the safety of nuclear power plants. It is still a challenge to accurately describe the dynamic performance of HTHP PRVs. In this study, the accuracy of computational fluid dynamics (CFD) based modelling of the transient processes is examined. For one of the HTHP PRVs named DWPRV, the effects of different parameters on the dynamic performance were investigated by combining CFD simulation and experiments. In the simulation, the domain decomposition method (DDM) and the Grid Pre-deformation Method (GPM) were adopted to handle the moving disk geometry and the large mesh deformation. The effect of damping was also studied. It is confirmed that the use of CFD simulation can improve the design and settings of a HTHP PRV in a highly energetic service that is difficult to test due to safety reasons. For the DWPRV, it was found that the maximum flow rate occurs when the curtain area is 1.18 times the throat area. The degree of superheat ranging from $0 \mathrm{C}$ to $100 \mathrm{C}$ has a negligible effect on the performance of DWPRV regardless of the changes in the material mechanical properties with operating temperatures. The reseating pressure increases linearly with the rise in the distance between the upper adjusting ring and the sealing face. The lower adjusting ring exhibits a weak effect on the reseating pressure. For the ratios of rated lift to throat diameter equalling to 0.3 and 0.35 , the DWPRV exhibits the higher blowdown for the ratio of 0.35 .
\end{abstract}

\section{Introduction}

A pressure relief valve (PRV) is a significant safety accessory ofpressure loaded installations. For nuclear or thermal power plants, PRVs act as the last passive protectors for the safety of the plant. It has been widely accepted that the reliable performance of a PRV is extremely important since its role in the nuclear leakage accident of Three Mile Island Nuclear Power Station in USA when the failure to close resulted in reactor core degradation. That accident is mainly attributed to a failure of one PRV (Rogovin, 1979). The safety of nuclear power plants is the focus worldwide considering that nuclear energy is one of the feasible solutions to replacing fossil fuels and the reduction of $\mathrm{CO} 2$. However, even though safety valves could be considered as a mature technology, ensuring reliability is still an area of concern. Since the performance of safety valves is related to their dynamic response the recent improvements in computational fluid dynamics (CFD) based simulation for fluid structure interaction techniques hold the promise of direct simulation of the processes and a better understanding of how safety valves behave under real conditions. This paper addresses the development of CFD techniques and their application to safety valve simulation by presenting the results of a study to establish the accuracy of such techniques by comparison with blowdown data and measurement of the valve response. In practice, the requirement of safety valves to open and close at preset pressures is a challenging design task. For example, ASME I type valves can be required to open with $3 \%$ of set pressure and close within $4 \%$ of set pressure. This is commonly achieved by nozzle rings to control the flow path and pressure forces on the valve disk and established by trial and error on a test bench. Alternatively, CFD techniques have the potential for accurately determining these characteristics and help inform designers of appropriate disk and nozzle geometries and spring selection.

This paper examines some of these issues using CFD based transient simulation techniques. Over the past 30 years, experimental investigations on PRVs have made steady progress. In the 1980's, Sallet et al. experimentally studied the flow fields and pressure distribution inside a typical PRV (Sallet et al., 1980; Sallet, 1984) and developed a simplified semi-empirical equation for the prediction of critical mass flow rate through PRVs (Sallet, 1991). Singh et al. (1982). studied the valve dynamic behavior and observed chattering under subcooled liquid 
and vapor flow conditions. To investigate the effects of flow force, Narabayashi et al. (1986). conducted experiments on PRVs using steam-liquid two-phase flow and subcooled water. Their results showed that the reaction force of the two-phase flow and subcooled water to the valve stem was similar to steam flow and therefore independent of two phase conditions. Betts and Francis (1997) measured the pressure distribution on the underside of a commercial PRV disk when the PRV was subject to a choked compressible flow. However, in general experimental studies at high temperature and pressure steam (HTHP) are expensive, difficult to carry out resulting in limited data being available for these conditions. The HTHP steam here is defined as the steam whose pressure exceeds $10 \mathrm{MPa}$ and the temperature is equal to or higher than $312 \mathrm{C}$ (the saturation temperature at $10 \mathrm{MPa}$ ) in reference to the standard of Supervision Regulation on Safety Technology for Stationary Pressure Vessel (TSG) 21-2016 which defines the high pressure vessel. With the development of CFD techniques and low cost high performance computers, numerical simulation has been increasingly applied to the study of PRVs. The steady state simulations of PRVs were reported by several research groups. Kim et al. (2006). carried out a computational study using the two-dimensional, axisymmetric, compressible Navier-Stokes equations to study the gas flow between the PRV's nozzle exit and valve seat. Vu et al. (1994). investigated the complex three-dimensional flow field of an oxygen PRV during an incident by CFD analysis. The computational result indicated the formation of vortices near the opening of the valve which matched the erosion pattern of the damaged hardware. Moncalvo et al. (2009). discussed flow domain discretization requirements and the effect of the turbulence model on the reproduction accuracy of air mass flow rates in two PRVs using the CFX commercial CFD software. They concluded that the grid resolution is the decisive factor affecting the exactness of the calculations. With regard to the turbulence model, two equation systems were found to be sufficient with the Shear Stress Transport (SST) turbulence model showing the best accuracy. A common approach in the literature is to assume quasi-static conditions apply and examine the steady state behavior of the valve: this has been done both experimentally and computationally. Francis and Betts (1997) used the commercial software code FIDAP to predict an axisymmetric incompressible flow pattern inside a PRV. Experimental and simulation results were compared in the pressure distribution and force imposed on the valve disk. Dempster et al. (2006). conducted a CFD analysis on the characteristics of a conventional gas spring PRV operating at 10-20 bar. The CFD results for mass flow and force agreed well with the experimental data for a range of disk lifts. Similar studies were carried out by Kourakos et al. (2013). who investigated the flow force exerted on the valve disk with different inlet pressures and lift positions by experiments. Numerical simulations were performed in a 2D axisymmetric model of the valve for validation. Carneiro et al. (2012). studied the dynamic behavior of a commercial spring-type PRV. Experimental results were obtained for the valve discharge coefficient as a function of the valve opening fraction for steady state and transient flow conditions. A comparison of experiments and numerical simulations results displayed remarkably good agreement. In the study by Schmidt et al. (2009). on high pressure PRVs, an equation describing the critical mass flow rate of polyethylene and synthesis gas through a nozzle was derived. This equation was compared with a model presented in the ISO standard EN-ISO 4126-1 and the experimental data. The numerical results showed that the discharge coefficient of a PRV measured at moderate pressures can be extrapolated to high pressures if it is used in conjunction with the nozzle flow model for polyethylene and synthesis gases. For a PRV, the dynamic performance is more important than the steady state one. For the study of the dynamic performance of a PRV, transient simulation is an important method and has been reported by several groups. The details can be found in Table 1 [16-17,18,19,20,21,22]. Especially, Song et al (Rogovin, 1979; Song et al.,2013, 2014). made great progress in the transient simulation of a PRV. They firstly developed a 3-D CFD model in combination with dynamics equations to describe the fluid characteristics and dynamic performance of a spring-loaded PRV. In their studies, a moving mesh and the domain decomposition method (DDM) were introduced to the transient analysis. Despite the progress Song et al. achieved, there are still several problems that need to be addressed. Only the reseating pressures were used to verify their transient simulation results. The simulations by Song et al. are limited to air at less than $1 \mathrm{MPa}$ (the pressure value hereafter refers to gauge pressure). For HTHP PRVs which features critical flow, neither experiments nor transient simulations can be found. Especially, HTHP PRVs usually have flexible disks whose shapes are complex, resulting in difficulties in domain decomposition and grid generation. In addition, in the simulations by Song et al. the gravitational force of valve disk components such as valve disk, valve spindle, disk holder and spring were not taken into consideration, likely leading to deviations of simulation results from the actual ones. Therefore, it is still a challenge to accurately simulate the dynamic performance of HTHP PRVs. In 


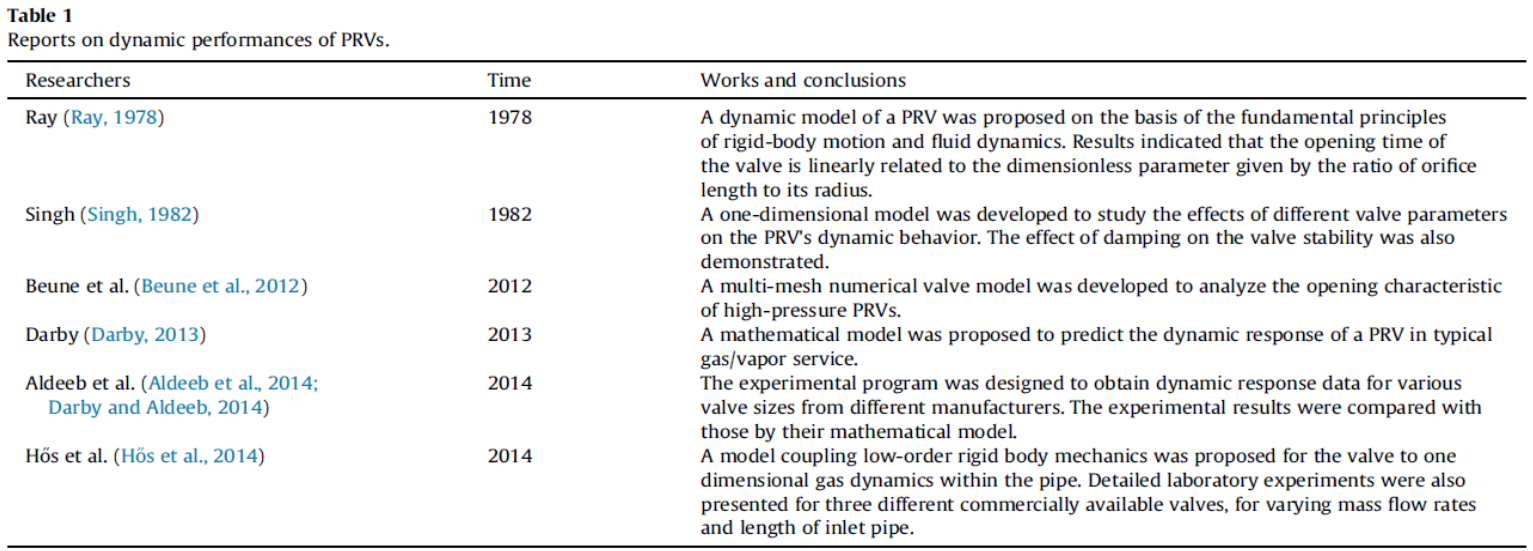

this paper a number of challenges are investigated. We build upon the developments of Song et al. (2014). and show the accuracy of transient CFD approaches to predict the dynamic response of the valve under high pressure and temperature opening and closure conditions. To address this challenge, an experimental arrangement was established for the testing of HTHP PRVs in accordance with the ASME PTC 25 standard. The dynamic performance of the HTHP PRVs was recorded. For the transient simulation of the HTHP PRVs, the Grid Predeformation Method (GPM) was adopted to handle the complex shape of the flexible disk and the large mesh deformation that occurs when the disk is moving. Furthermore, we also investigate the influence of modelling the exit boundary condition. It is common to place an atmospheric boundary condition at the valve flange exit. However, in this study the external atmosphere is also modelled to capture aspects of the surrounding flow field as the flow exits the valve as a jet. The opportunity is also taken to show the value of the simulation technique to valve design and operation by investigating the effects of controlling parameters on the dynamic performance of HTHP PRVs, i.e., fluid properties, superheat temperature, adjusting ring position, and rated lift.

\section{Experimental facility and testing}

In this study, a HTHP PRV was provided by Wujiang Dongwu Machinery Co. Ltd, China. The set pressure, rated lift, throat size are $12.22 \mathrm{MPa}, 22.5 \mathrm{~mm}$, and $57.8 \mathrm{~mm}$, respectively. Hereafter, this PRV is specifically referred to as DWPRV. Fig. 1 shows the experimental setup of the PRV performance testing. The test system arrangement and test procedure are in accordance with the ASME PTC 25 standard.

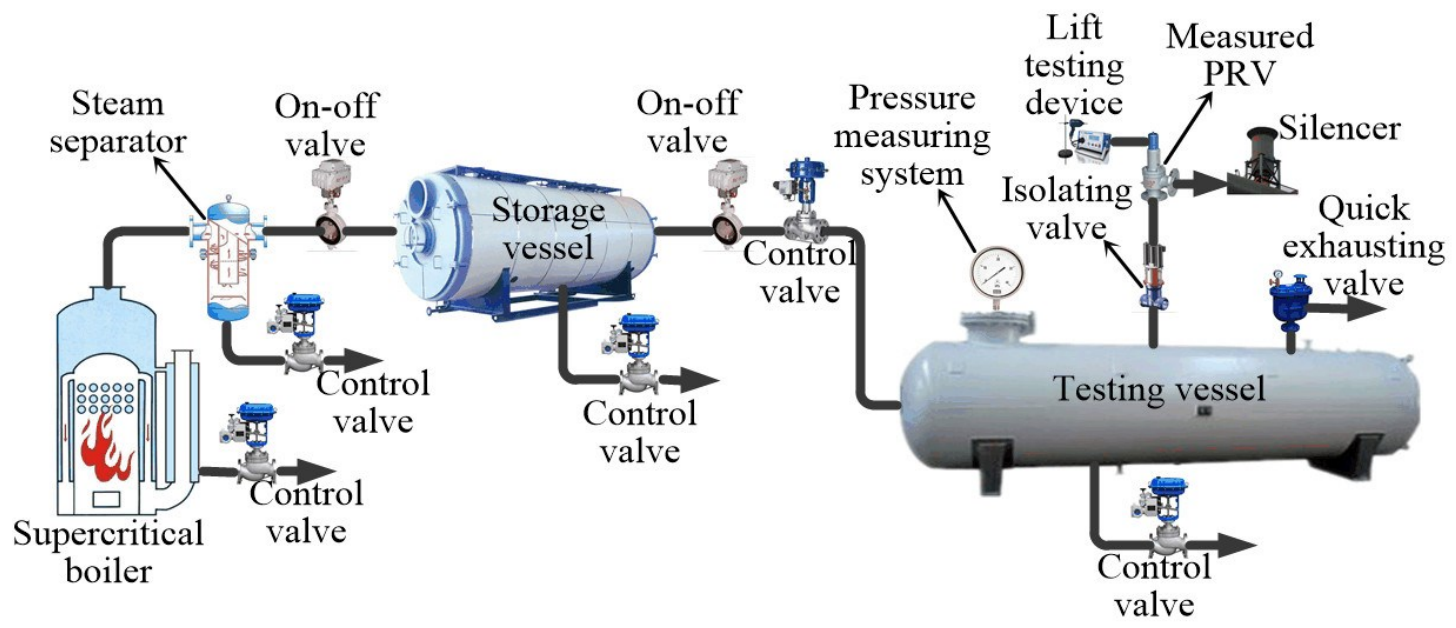

Fig.1.HTHP PRV experimental setup

A supercritical pressure boiler supplied saturated steam to a storage vessel which stored high pressure steam. The PRV for testing was mounted on a testing vessel. During the testing, the pressures of the storage vessel and 
test vessel were slowly increased to $90 \%$ of the expected set pressure of the PRV. Then, the increase in the pressure of the test vessel was carefully controlled below 13,800 Pa s_1 until the PRV popped by introducing a flow rate of steam from the storage vessel into the test vessel. The lift of the tested PRV, the pressure of the test vessel, and the pertinent characteristics of the tested PRV were observed and recorded. The measurement accuracies of pressure transmitter (BP201/501Z, Hefei Sentech Sensing instruments Co. Ltd.) and displacement transducer (ZS-LD200, OMRON) are $\pm 0.5 \%$ and $\pm 0.2 \%$, respectively. The PLC (S7-300, Siemens) collected the data and its time resolution of the data acquisition is $10 \mathrm{~ms}$ which was checked by the high speed camera (Motion Xtra N4, IDT). Fig. 2 shows a sectioned 3-D model of the DWPRV studied in this research. Fig. 3 is a photograph of the DWPRV at a fully open condition during the performance testing. A silencer was connected to the outlet of the DWPRV to lower the discharge noise and to ensure a desirably low back pressure.

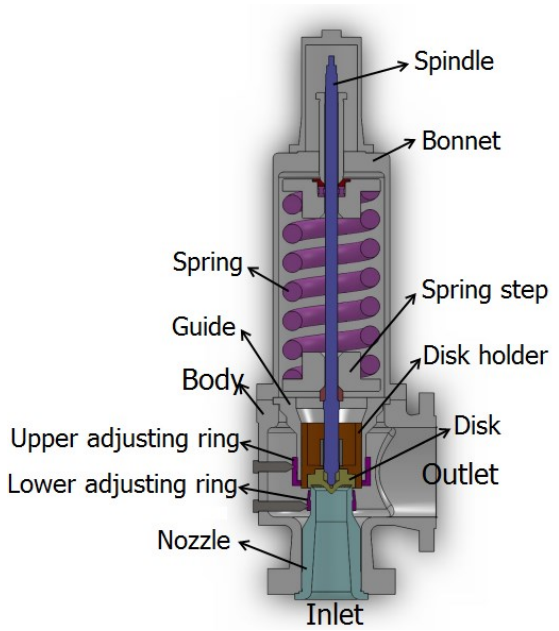

Fig. 2. Schematic representation of HTHP PRV

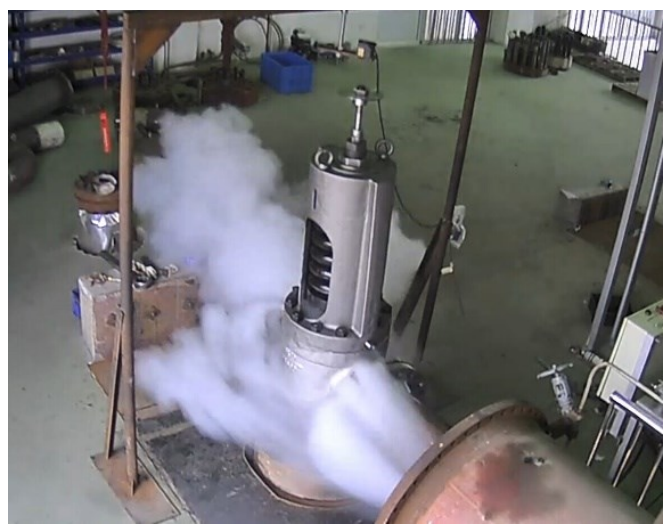

Fig. 3. Photo of a HTHP PRV at full open during performance test

\section{Simulation analysis}

The simulation was carried out using the commercial software ANSYS CFX 14.0 (ANSYS, 2011). To model the low, the High Resolution, Second Order Backward Euler and High Resolution options were used in the advection scheme, transient scheme and Turbulence numerics, respectively. Standard wall functions were used to remove the need to grid the boundary layer. In this simulation, a half-symmetrical model was used to reduce the computation time. The SST turbulence model was adopted for turbulence closure in accordance with the study by Moncalvo et al. (2009). The volume of the inlet vessel was $10 \mathrm{~m}^{3}$ which was equal to the value of the test vessel during the performance test. Dry saturated steam as the working medium was used unless otherwise noted. The displacement of the valve disk was determined using a single degree of freedom model in reference to the report by Song et al. (2014). The motion of the disk is at all times based on a force balance. Deduced from Newton's second law, the following second order ordinary differential equation used to simulate the motion of the valve disk can be described as Eq. (1):

$$
\mathrm{m}_{\text {movable }} \ddot{y}=F_{\text {flow }}-\xi \dot{y}-F_{\text {spring }}-G_{\text {disk }}
$$

and $m_{\text {movable }}$ and $G_{\text {disk }}$ can be written as:

$$
\begin{aligned}
m_{\text {movable }}= & 0.5 m_{\text {sring }}+m_{\text {spindle }}+m_{\text {disk-hoder }}+m_{\text {disk }} \\
& +m_{\text {bearing-seating }} \\
G_{\text {disk }}=( & m_{\text {sring }}+m_{\text {spindle }}+m_{\text {disk-hoder }}+m_{\text {disk }}+m_{\text {bearing }} \\
& \left.+2 m_{\text {bearing-seating }}\right) \times g
\end{aligned}
$$


where $m_{\text {spring, }} m_{\text {spindle, }} m_{\text {disk-holder, }} m_{\text {disk, }}, m_{\text {bearing }}$ and $m_{\text {bearing-seating }}$ are the masses of the spring, spindle, disk holder, disk, bearing and bearing seating, respectively; $\ddot{y}$ is the acceleration of the moving part in the moving direction; $\dot{y}$ is the disk velocity; Fflow is the force applied by flowing fluid; $F_{\text {spring }}$ is the spring force acting on the disk; $x$ is the damping coefficient. The $\ddot{y}$ in Eq. (1) can be discretized into discrete difference form:

$$
\ddot{y}=\frac{\dot{y}_{t+\Delta t}-\dot{y}_{t}}{\Delta t}
$$

where Dt is the time step defined in CFX. The velocity $\dot{y}$ can be further discretized as:

$$
\dot{y}_{t+\Delta t}=\frac{y_{t+\Delta t}-y_{t}}{\Delta t}
$$

The lift of the disk $\mathrm{yt}_{\mathrm{t}}$ also appears in the expression for spring force:

$$
\mathrm{F}_{\text {spring }}=y_{\mathrm{t}} \cdot k_{\text {spring }}+F_{0}+F_{0.5}
$$

where $F_{0}$ and $F_{0.5}$ can be written as:

$$
\begin{aligned}
& F_{0}=\Delta y_{0} \cdot k_{\text {spring }} \\
& F_{0.5}=0.5 \cdot k_{\text {spring }}
\end{aligned}
$$

where $k_{\text {spring }}$ is the stiffness of spring; $F_{0}$ is the force applied by the steam on the disk at the set pressure; $D_{y 0}$ is the spring initial compression. The value of 0.5 is the initial lift to establish a continuous flow field at the first calculation step. The discrete form of the motion equation is re-assembled, and the disk displacement is finally isolated as:

$$
y_{t+\Delta t}=\frac{F_{\text {flow }}-\xi \dot{y}_{t}-F_{0}-G_{\text {disk }}-F_{0.5}+\frac{m_{\text {movable }}}{\Delta t^{2}} y_{t}+\frac{m_{\text {movable }}}{\Delta t} \dot{y}_{t}}{\frac{m_{\text {movable }}}{\Delta t^{2}}+k_{\text {spring }}}
$$

Since ANSYS CFX cannot read and execute Eq. (9) directly, the CFX expression language (CEL) was used to solve and couple Eqs.(1)-(9) for the CFD simulation (Song et al., 2010). The source code manipulation to the CEL can be found in Table S1 of supplementary materials.

\subsection{Domain decomposition and grid generation}

A pure structural grid (hex mesh) was generated to ensure no element with a negative volume or poor quality occurred at any iteration when the disk was moving. To generate the structural meshes easily, the domain decomposition method (DDM) was used as in the study by Song et al. (Darby, 2013). To handle the critical flow at the outlet of the DWPRV, a domain representing the external surroundings with atmospheric boundaries was connected to the outlet of the DWPRV. Fig. 4 shows the mesh model of the four domains. The domains were connected by four general grid interfaces (GGIs). To account for a potential discontinuity at the valve opening a small initial lift of $0.5 \mathrm{~mm}$ was used to establish a continuous flow field at the first calculation step. As mentioned in the study by Song et al. (Darby, 2013), the DDM can solve the problem of distorted coarsely deformed mesh caused by the influence of so-called mesh stiffness from the nearest wall boundary in the iteration process. Fig. $5(\mathrm{a})$ and (b) shows the initial mesh and the corresponding deformed mesh at the rated lift $(22.5 \mathrm{~mm})$ of the DWPRV by using DDM, respectively. The computation failed during the mesh deformation because the distorted coarsely deformed mesh caused a large decrease in the mesh quality. To address this problem, GPM was adopted in this study. As shown in Fig. 5(c) and (d), by the pre-deformation of the mesh nodes, the quality of the deformed mesh was enhanced as indicated, thus ensuring computational accuracy. It should be noted that the use of additional domains may likely enhance the quality of the deformed mesh. However, the interface number rises with the increase in domain number, giving rise to increases in computation time and cost. 


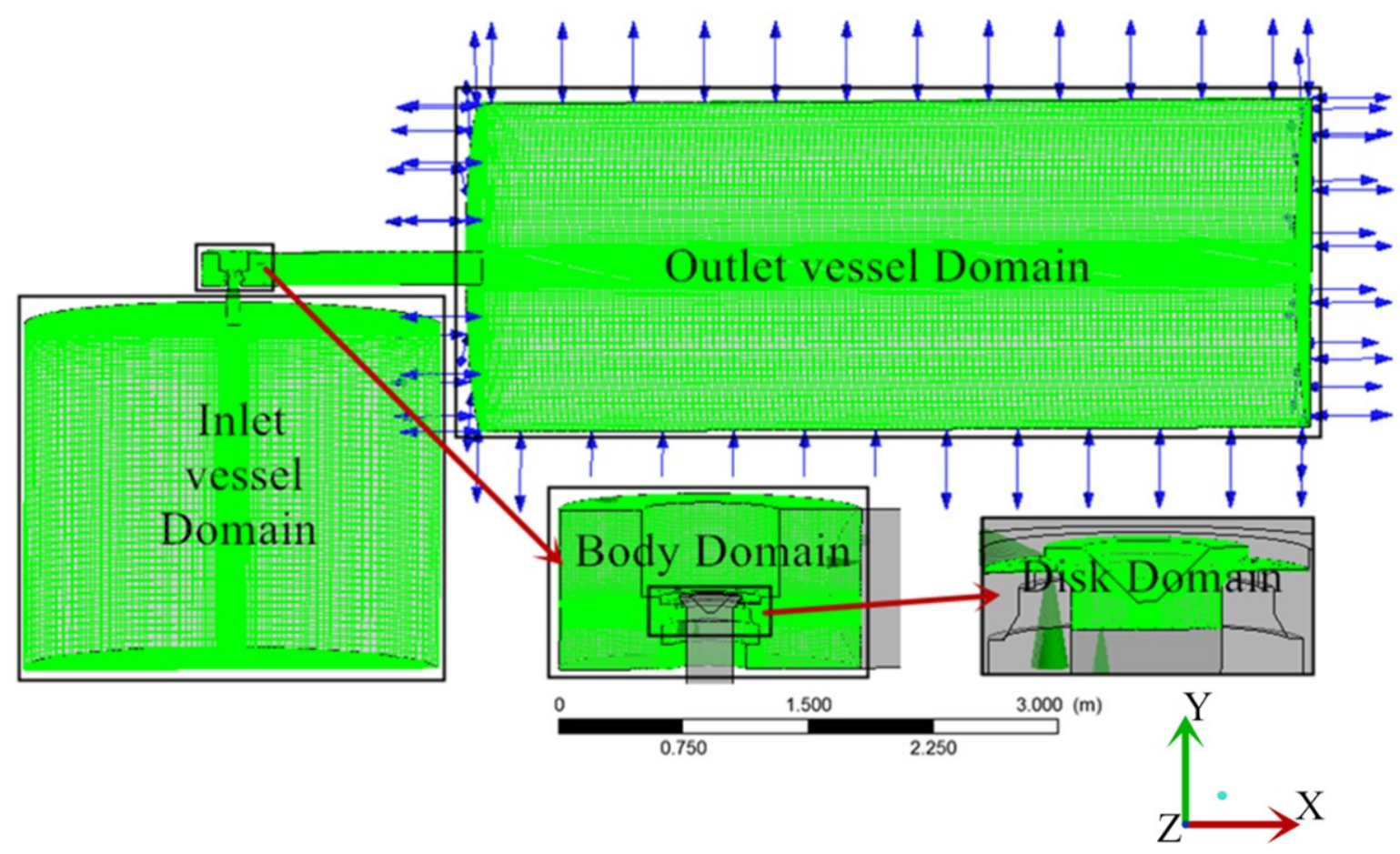

Fig. 4. Position relationship of each domain.
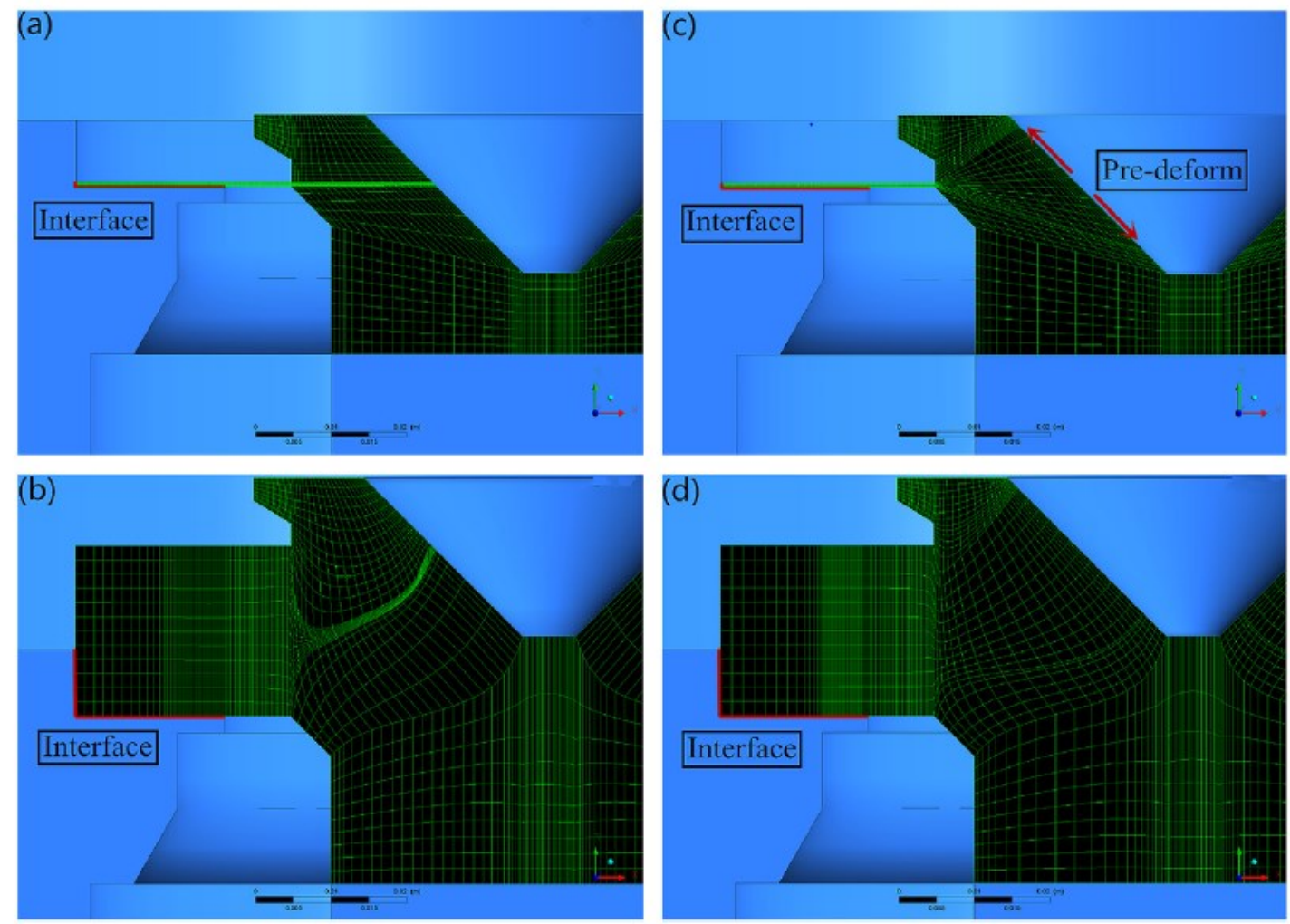

Fig. 5. Initial and deformed meshes by different mesh generation methods: (a) initial mesh using DDM; (b) deformed mesh at the rated lift of $22.5 \mathrm{~mm}$ using DDM; (c) initial mesh using DDM and GPM; (d) deformed mesh at the rated lift of $22.5 \mathrm{~mm}$ using DDM and GPM

\subsection{Boundary conditions}

Fig. 4 shows the computational mesh and boundary conditions. The disk can move in the y direction according to Eq. (9). The reference pressure over all the domains was defined as atmospheric pressure. The pressure of the inlet vessel domain was set to be $12.22 \mathrm{MPa}$ which agreed with the experimental value. The initial pressures 
of the other domains were set to be $0 \mathrm{MPa}$. The external domain boundary pressures were defined as $0 \mathrm{MPa}$ and an open boundary condition.

\subsection{Mesh independence}

The impact of mesh fineness was investigated by determining the lifting force of the PRV, which has a significant influence on the dynamic performance of the disk and the whole simulation accuracy. To reduce computational time, the investigation was carried out for the first $50 \mathrm{~ms}$ of the whole dynamic performance since the valve was fully open by this time and the maximum flow reached. Three mesh densities have been generated and the number of elements are 0.5 million (coarse), 1 million (fine) and 1.5 million (fine) respectively. The calculation was terminated only when the residual root mean square (RMS) error values were strictly below $10^{-5}$. The results of a grid independence study indicated that there is no obvious difference in the lifting force between fine and very fine model, but it is different from the coarse one. This indicates that the calculation of the lifting force is relatively independent for the fine and very fine models. To minimise computation time, the fine mesh density (1 million elements) was chosen for this transient study.

\subsection{Variable time steps}

A PRV commonly undergoes three stages in the dynamic process: rapid open, stable discharge, and re-closing. The three stages have different durations. Hence, to optimize the computational time and to ensure convergence, a variable time step (altogether five time steps) was used during the different stages. The five time steps were determined by several repeated attempts to avoid the interruption of calculation and to save the computation time. A time step of $5 \mathrm{~ms}$ was chosen in the first $1 \mathrm{~ms}$ (200 steps), which was set to ensure calculation convergence. When the disk began to rise, a slightly larger time step of $50 \mathrm{~ms}$ was used, which could simulate the opening process $(50 \mathrm{~ms})$ sufficiently. When the disk achieved its rated lift, a large time step of $0.5 \mathrm{~ms}$ was used. A smaller time step of $0.1 \mathrm{~ms}$ was used to capture the disk movement and fluid field during the closure process accurately. At last, a time step of $50 \mathrm{~ms}$ was used to ensure the disk could completely reseat.

\section{Results and discussions}

\subsection{Performance of DWPRV}

Given the existence of critical flow at the outlet of the DWPRV, the definition of the pressure at the DWPRV outlet during simulation is difficult. Therefore, in our study, the discharge flow into the surroundings was modeled explicitly to avoid the direct definition of the pressure at the DWPRV flange outlet. The inlet vessel pressure as a function of discharge time of the DWPRV is illustrated in Fig. 6(a). The inlet vessel pressure decreases continuously with the discharge from the DWPRV. The reseating pressure, blowdown, and discharge time are $10.695 \mathrm{MPa}, 12.480 \%$, and approximately $1276 \mathrm{~ms}$, respectively.

As presented in Table 2, the simulation value is in good agreement with the experiment alone. The difference of blowdown between the simulation and the experimental values is $0.204 \%$. In comparison with the results of the DWPRV with and without the outlet vessel, no difference in the PRV dynamic performance can be found. The mass flow rates for the two cases are the same, e.g. $37.8 \mathrm{~kg} \mathrm{~s}^{-1}$ at 50 ms of discharge time. As shown in Fig. 7(a) and (b), the two pressure contours around the disk are nearly the same. However, when the external surroundings are modeled explicitly the local flange exit pressure is higher and the density is increased resulting in the maximum velocity at the outlet of the DWPRV decreasing from 920 to $760 \mathrm{~m} \mathrm{~s}^{-1}$ (see Fig. 7(c)-(f)). While the modelling of the external environment has little impact on the valve dynamics for this case, its inclusion would be necessary to more accurately calculate the noise and the flow force at the outlet when the PRV is discharging because the discharging noise and flow force at the outlet depend on the velocity at the outlet. 

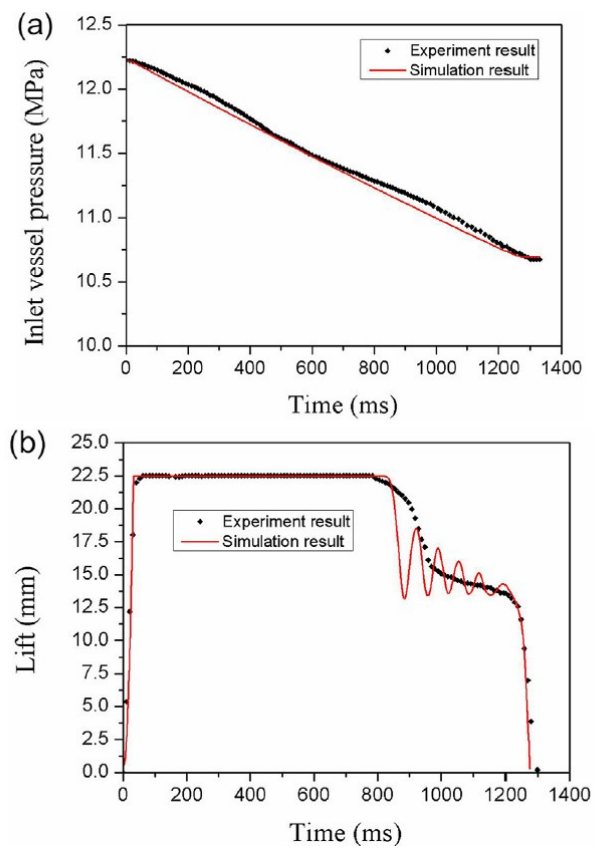

Fig. 6. The inlet vessel pressure (a) and lift (b) as a function of discharge time of DWPRV $\left(k_{\text {spring }}=743 \mathrm{Nm}^{-1}\right.$; throat size of $57.8 \mathrm{~mm}$ in diameter; the distance between the lower adjusting ring and the sealing face $\left(h_{1}\right)$ is $2.2 \mathrm{~mm}$; dry saturated steam; the distance between the upper adjusting ring and the sealing face $\left(h_{2}\right)$ is $8.7 \mathrm{~mm}$ above the sealing surface).

Table 2

Performance comparison for simulation and experiment result of DWPRV

\begin{tabular}{lll}
\hline & Experiment & Simulation \\
\hline Set pressure (MPa) & 12.22 & 12.22 \\
Reseating pressure (MPa) & 10.670 & 10.695 \\
Blowdown (\%) & 12.684 & 12.480 \\
Discharge time (ms) & 1300 & 1276 \\
Popping time (ms) & 50 & 32 \\
\hline
\end{tabular}

${ }^{\text {a }} k_{\text {spring }}=743 \mathrm{~N} \mathrm{~mm}^{-1}$; throat size is $57.8 \mathrm{~mm}$ in diameter; $h_{1}=2.2 \mathrm{~mm}$; $h_{2}=8.7 \mathrm{~mm}$; dry saturated steam.

The lift of the DWPRV as a function of discharge time is illustrated in Fig. 6(b). The DWPRV achieves full opening at around $32 \mathrm{~ms}$. The valve remains open until $810 \mathrm{~ms}$ but incurs fluttering with five cycles. This fluttering was not detected in the corresponding experiment. For a PRV, the friction between disk holder and disk guide acts as damping, thus weakening disk fluttering. In the above simulation, the friction was neglected $(\xi=0)$. To study the effect of the damping on disk fluttering, variations in the damping coefficient, $\xi$ values ranging from 3000 to $9000 \mathrm{~N} \mathrm{~s} \mathrm{~m}^{-1}$ was investigated. The results are shown in Fig. 8 and Table 3. When $\xi$ increases from 3000 to 9000 $\mathrm{N} \mathrm{s} \mathrm{m}^{-1}$, the fluttering gradually disappears and the popping time increases from 38 to $54 \mathrm{~ms}$ which is close to the experimental value. The simulation results predict a faster initial reseating versus the experimental one (in the $800-1000$ ms region) (Fig. 8(a)). This is because the effect of friction is simplified as the damping coefficient of $\xi$ but as a matter of fact this friction is very complicated. Meanwhile, the discharge time increases from 1299 to $1338 \mathrm{~ms}$ and the reseating pressure slightly deceases from $10.672 \mathrm{MPa}$ to $10.644 \mathrm{MPa}$. Given the negligible effect of $\xi$ on the blowdown value, $\xi$ was taken as zero in the following simulations. 

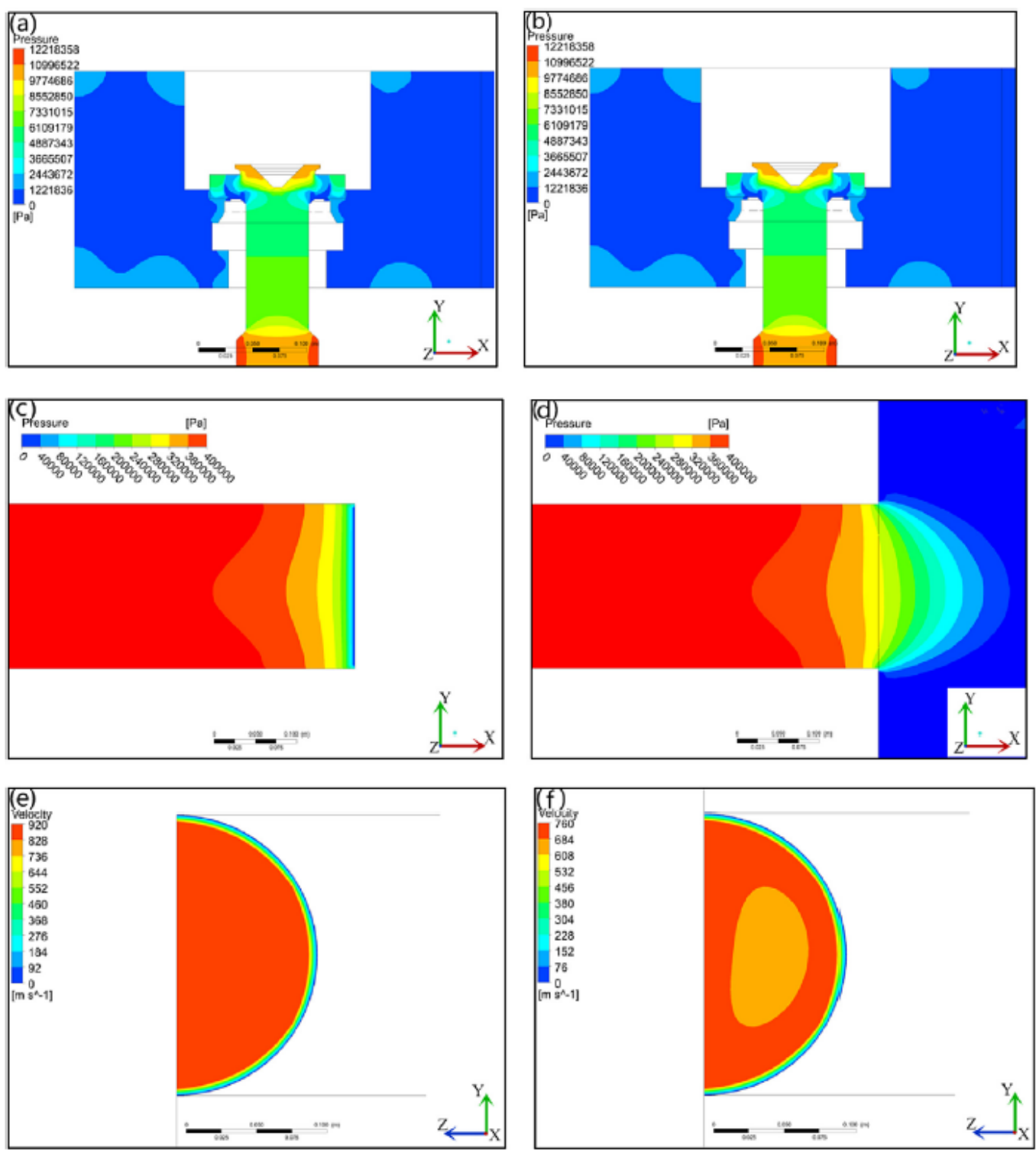

Fig. 7. Influence of the outlet vessel on the pressure and velocity contours $\left(k_{\text {spring }}=743 \mathrm{~N} \mathrm{~mm}^{-1}\right.$; throat size of 57.8 $\mathrm{mm}$ in diameter; $h_{1}=2.2 \mathrm{~mm} ; h_{2}=8.7 \mathrm{~mm}$; dry saturated steam; $t=50 \mathrm{~ms}$ : pressure contours around the disk without (a) and with (b) outlet vessel; pressure contours at the PRV outlet without (c) and with (d) outlet vessel; velocity contours at the PRV outlet without (e) and with (f) outlet vessel.

While the modelling of the external environment has little impact on the valve dynamics for this case, its inclusion would be necessary to more accurately calculate the noise and the flow force at the outlet when the PRV is discharging because the discharging noise and flow force at the outlet depend on the velocity at the outlet.

At $1276 \mathrm{~ms}$, the DWPRV reseats. The evolution of lifting force, spring force, and resultant force (the sum of lifting force and spring force) applied on the disk with the discharge time is demonstrated in Fig. 9. The lifting force is high enough to ensure the resultant force is upward before the DWPRV starts to reseat $(810 \mathrm{~ms})$. This continually upward resultant force gives rise to a stable and complete opening process. From 810 to $1200 \mathrm{~ms}$, the alternately upward and downward resultant forces are observed before the DWPRV starts to reseat again (around 1200 $\mathrm{ms})$. 

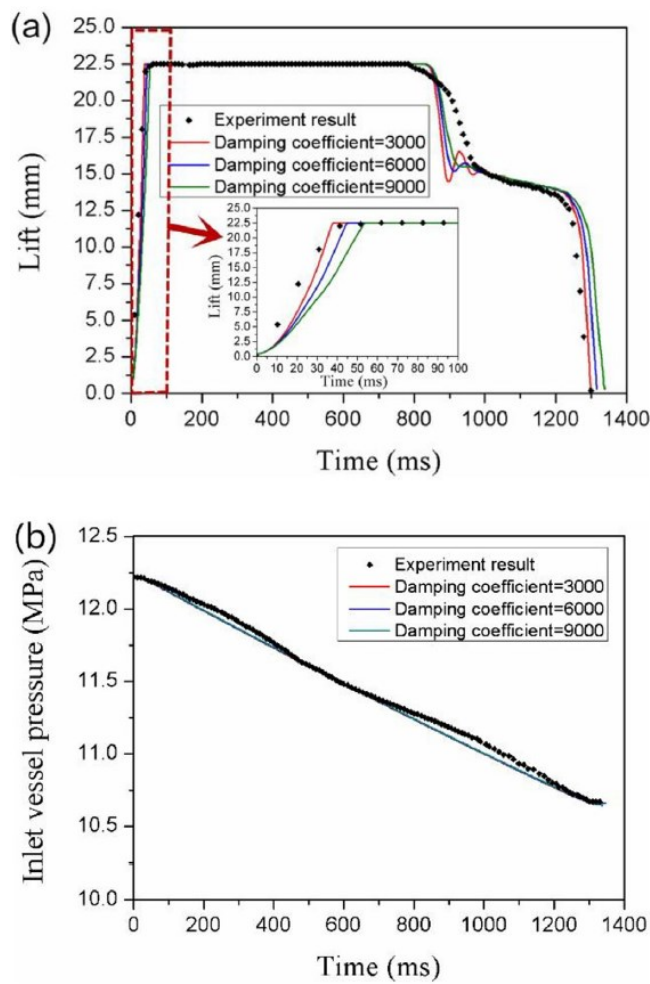

Fig. 8. The lift (a) and inlet vessel pressure (b) as a function of discharge time of DWPRV with different damping coefficient ( $k_{\text {spring }}=743 \mathrm{~N} \mathrm{~mm}^{-1}$; throat size of $57.8 \mathrm{~mm}$ in diameter; $h_{1}=2.2 \mathrm{~mm} ; h_{2}=8.7 \mathrm{~mm}$ ).

Table 3

Effects of various damping coefficients on the dynamic performance of DWPRV

\begin{tabular}{lllll}
\hline & Experiment & $\xi=3000$ & $\xi=6000$ & $\xi=9000$ \\
\hline Set pressure (MPa) & 12.22 & 12.22 & 12.22 & 12.22 \\
Reseating pressure (MPa) & 10.670 & 10.672 & 10.659 & 10.644 \\
Blowdown (\%) & 12.684 & 12.667 & 12.774 & 12.897 \\
Discharge time (ms) & 1300 & 1299 & 1317 & 1338 \\
Popping time (ms) & 50 & 38 & 45 & 54 \\
\hline
\end{tabular}

${ }^{\mathrm{a}} k_{\text {spring }}=743 \mathrm{~N} \mathrm{~mm}^{-1}$; throat size is $57.8 \mathrm{~mm}$ in diameter; $h_{1}=2.2 \mathrm{~mm}$; $h_{2}=8.7 \mathrm{~mm}$; dry saturated steam.

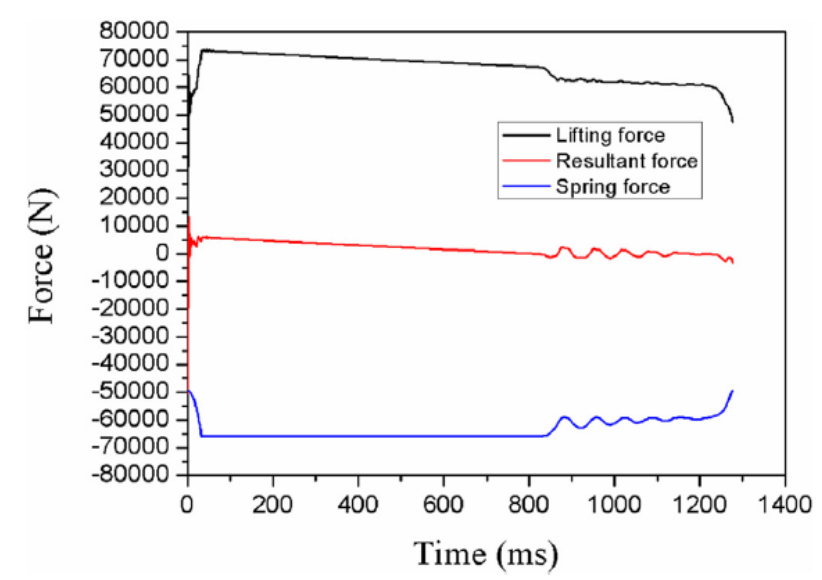

Fig. 9. The lifting force, spring force and resultant force as a function of discharge time of DWPRV (the vertical upward force along the spindle is positive, $k_{\text {spring }}=743 \mathrm{~N} \mathrm{~mm}^{-1}$; throat size of $57.8 \mathrm{~mm}$ in diameter; $h_{1}=2.2 \mathrm{~mm}$; $h_{2}=8.7 \mathrm{~mm}$; dry saturated steam). 
The Mach number profiles inside the DWPRV at various discharge times are shown in Fig. 10. At the discharge time of $5 \mathrm{~ms}$ (corresponding to the lift of $0.98 \mathrm{~mm}$ ), the Mach number at the throat is 0.058 . The maximum velocity (Mach number $=3.30$ ) appears at the gap between the disk holder and the lower adjusting ring. When the discharge time increases to $20 \mathrm{~ms}$, the Mach number at the throat is 0.436 . The maximum velocity still exists at the gap between disk holder and lower adjusting ring and the corresponding Mach number decreases to 2.83 . At $23.6 \mathrm{~ms}$, the throat area is equal to the curtain area and the Mach number at the throat is 0.661 . In this case, a new high Mach number zone (Mach number $=2.22$ ) emerges at the gap between the upper and lower adjusting rings beside the high Mach number zone at the gap between the disk holder and the lower adjusting ring. At $25.8 \mathrm{~ms}$, the throat area is 1.18 times that of the throat area and the Mach number at the throat is 0.878 . The flow rate achieves the highest value. At $27.8 \mathrm{~ms}$, the Mach number at the throat achieves 1 (corresponding to the lift of $16.9 \mathrm{~mm}$ ). The fully open condition (lift $=22.5 \mathrm{~mm}$ ) is obtained at $32 \mathrm{~ms}$ when a third high Mach number zone occurs at the nozzle outlet. At $1274 \mathrm{~ms}$, the DWPRV experiences reseating and the velocity at the throat decreases to a Mach number of 0.029 , coinciding with a single high Mach number zone at the gap between the disk holder and the lower adjusting ring. The mass flow rate as a function of the ratio of curtain area to throat area is illustrated in Fig.11. The mass flow rate increases from 1.64 to $37.2 \mathrm{~kg} \mathrm{~s}^{-1}$ with the increase in the ratio of curtain area to throat area from 0.0425 to 1.18 , and then levels off. That is, the maximum mass flow rate emerges at the ratio (curtain area to throat area) of 1.18 not 1 for the DWPRV. This is of practical relevance since a ratio of 1 is often taken as the theoretical fully open and maximum flow condition in design studies. The multidimensional nature of flow in this valve determines that further opening is required before the choking location moves to the nozzle with implications for the valve spring specifications, as will be discussed later.
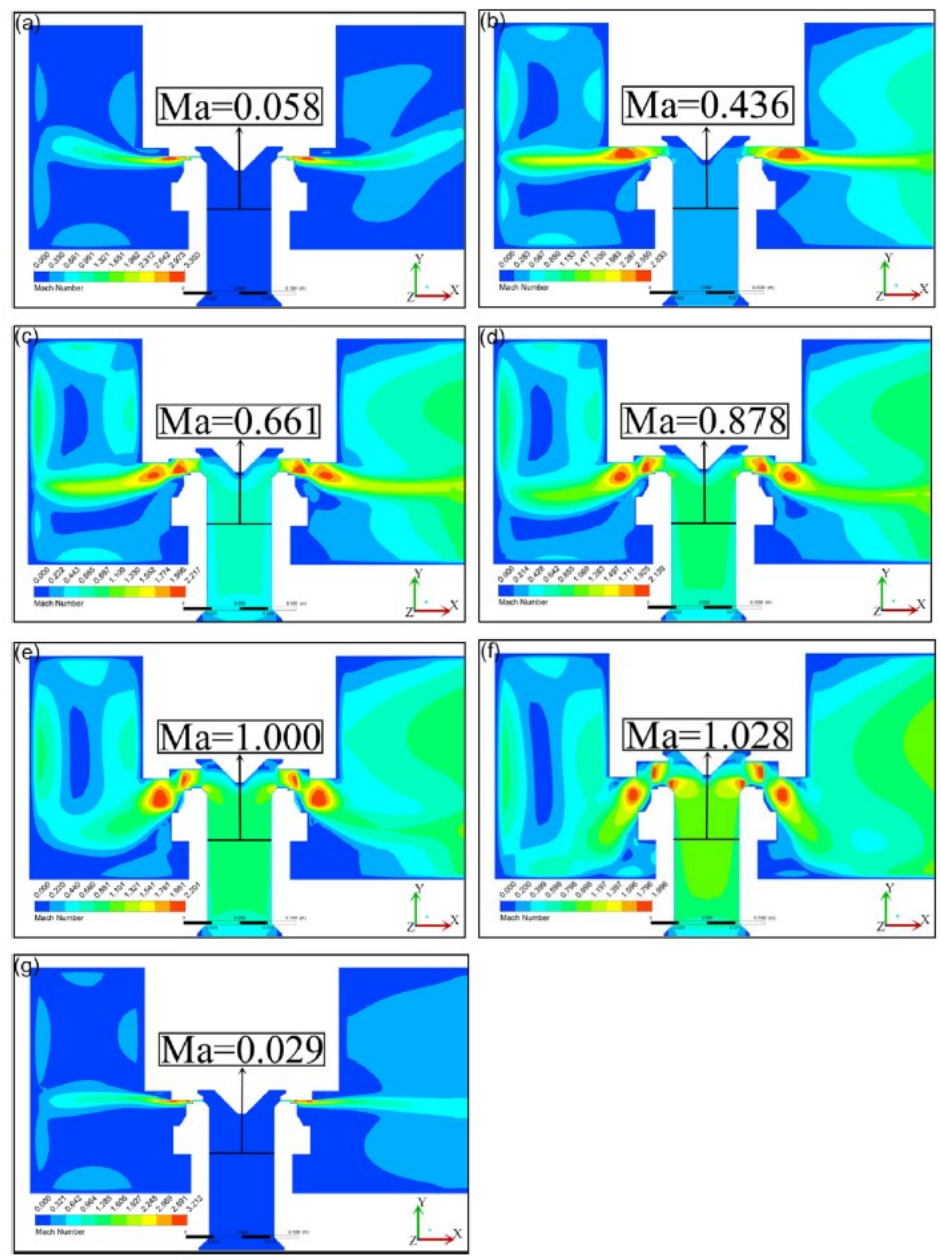

Fig. 10. Mach number profiles inside the DWPRV at various discharge time $\left(k_{\text {spring }}=743 \mathrm{~N} \mathrm{~mm}^{-1}\right.$; throat size of $57.8 \mathrm{~mm}$ in diameter; $h_{1}=2.2 \mathrm{~mm} ; h_{2}=8.7 \mathrm{~mm}$; dry saturated steam. (a) $t=5 \mathrm{~ms}$, lift $=0.98 \mathrm{~mm}$, and flow rate $=4.1 \mathrm{~kg} \mathrm{~s} 1$; (b) $t=20 \mathrm{~ms}$, lift $=8.95 \mathrm{~mm}$, and flow rate $=26.3 \mathrm{~kg} \mathrm{~s}^{-1}$; (c) $t=23.6 \mathrm{~ms}$, lift $=12.2 \mathrm{~mm}$, and flow rate $=33.7 \mathrm{~kg} \mathrm{~s}^{-1}$; (d) $t=25.8 \mathrm{~ms}$, lift $=14.5 \mathrm{~mm}$, and flow rate $=37.2 \mathrm{~kg} \mathrm{~s}^{-1}$; (e) $t=27.8 \mathrm{~ms}$, lift $=16.9 \mathrm{~mm}$, and flow rate $=37.9 \mathrm{~kg} \mathrm{~s}^{-1} ;(f) t=32 \mathrm{~ms}$, lift $=22.5 \mathrm{~mm}$, and flow rate $=37.6 \mathrm{~kg} \mathrm{~s} 1 ;(\mathrm{g}) t=1274 \mathrm{~ms}$, lift $=0.7 \mathrm{~mm}$, and flow rate $\left.=1.8 \mathrm{~kg} \mathrm{~s}^{-1}\right)$. 


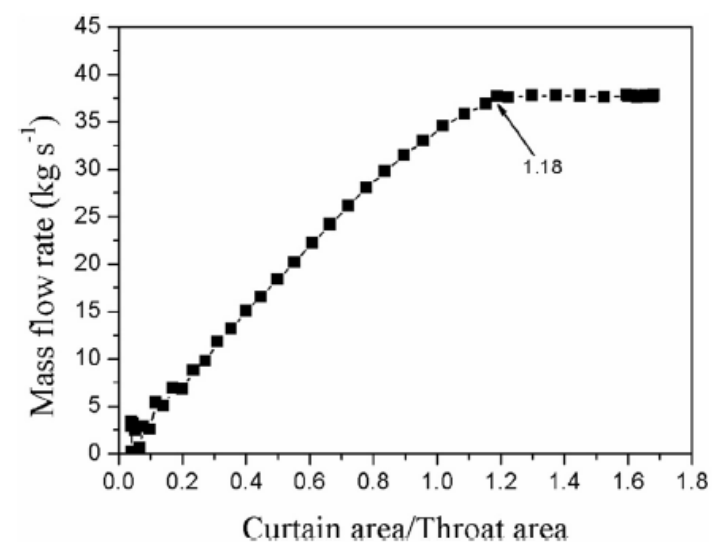

Fig. 11. Mass flow rate as a function of the ratio of curtain area to throat area for DWPRV $\left(k_{\text {spring }}=743 \mathrm{Nmm}^{-1}\right.$; throat size of $57.8 \mathrm{~mm}$ in diameter; $h_{1}=2.2 \mathrm{~mm} ; h_{2}=8.7 \mathrm{~mm}$; dry saturated steam).

\subsection{Effect of fluid physical properties}

Due to the difficulty of testing at real fluid conditions valves are often tested with high pressure, low temperature air and corrected for the real fluid conditions. Here we investigate the differences in valve response when using high pressure steam and air. This essentially investigates the effects of fluid properties on the DWPRV performance. Compressed air at room temperature was taken as the medium and the results were compared with that using dry saturated steam. As presented in Table 4, the reseating pressure of $11.071 \mathrm{MPa}$ for the case using compressed air, which is higher than that of $10.695 \mathrm{MPa}$ with dry saturated steam as the fluid. Therefore, the reseating pressure of the DWPRV is overestimated if compressed air is used as an alternative. When a HTHP PRV is used, this overestimation results in excessive steam discharge and an increase in the operation cost. In addition, the set pressure and simmer pressure usually decrease with the increase in medium temperature.

Table 4

DWPRV performances using dry saturated steam and compressed air ${ }^{2}$

\begin{tabular}{llllll}
\hline & Set pressure $(\mathrm{MPa})$ & Reseating pressure $(\mathrm{MPa})$ & Blowdown $(\%)$ & Reseating time $(\mathrm{ms})$ & Opening time $(\mathrm{ms})$ \\
\hline Steam & 12.22 & 10.695 & 12.480 & 1276 & 32 \\
Compressed Air & 12.22 & 11.071 & 9.402 & 1533 & 37 \\
\hline
\end{tabular}

${ }^{\mathrm{a}} k_{\text {spring }}=743 \mathrm{~N} \mathrm{~mm}^{-1}$; throat size is $57.8 \mathrm{~mm}$ in diameter; $h_{1}=2.2 ; h_{2}=8.7 \mathrm{~mm}$.

Our experimental results indicate the set pressure for the DWPRV using compressed air is 1.01-1.02 times that of the DWPRV using dry saturated steam. This is partly because the PRV material mechanical properties and seat geometry change at high temperature.

Fluid properties also rise during typical valve test conditions. In accordance with ASME PTC-25 standard, the steam conditions for flow capacity test shall be dry saturated steam, and the condition of the steam during the test at the device inlet shall be within limits of $98 \%$ minimum quality and $11.1 \mathrm{C}$ maximum superheat. However, no requirement of steam superheat can be found on the dynamic performance test of steam PRV. To address this issue, the effect of the superheat ranging from $0 \mathrm{C}$ to $100 \mathrm{C}$ on the dynamic performance of DWPRV was investigated by simulation. As presented in Table 5, a negligible decrease in reseating pressure can be observed when the superheat increases from $0 \mathrm{C}$ to $100 \mathrm{C}$. It should be noted that actually an excessively high superheat temperature weakens the material strength and the performance of the spring, and may have a complex effect on the sealing performance of HTHP PRV and an influence on the set pressure.

\begin{tabular}{|c|c|c|c|c|c|}
\hline 0 & 12.22 & 10.695 & 12.480 & 1276 & 32 \\
\hline 20 & 12.22 & 10.713 & 12.332 & 1244 & 32 \\
\hline 40 & 12.22 & 10.676 & 12.635 & 1259 & 32 \\
\hline 60 & 12.22 & 10.675 & 12.643 & 1241 & 32 \\
\hline 80 & 12.22 & 10.670 & 12.684 & 1231 & 32 \\
\hline
\end{tabular}

${ }^{\mathrm{a}} k_{\text {spring }}=743 \mathrm{~N} \mathrm{~mm}^{-1}$; throat size is $57.8 \mathrm{~mm}$ in diameter; $h_{1}=2.2 \mathrm{~mm} ; h_{2}=8.7 \mathrm{~mm}$. 


\subsection{Effect of upper and lower adjusting rings}

For HTHP PRVs, blowdown can be adjusted by changing the position of the adjusting ring (see Fig. 2). In a design context, it is desirable to accurately determine the position of the adjusting ring and how it influences valve opening and closing. So far, the desirable positions of the adjusting rings mostly depend on engineers' experience and repeated adjustments. As shown in Fig. 12(a), given the distance between the lower adjusting ring and the sealing face ( $h_{1}$, see Fig. 13) of $2.2 \mathrm{~mm}$, a roughly linear increase in the reseating pressure can be observed for the DWPRV from 9.077 to $10.695 \mathrm{MPa}$ with the rise in the distance between the upper adjusting ring and the sealing face ( $h_{2}$, see Fig. 13) from 2.7 to $8.7 \mathrm{~mm}$.
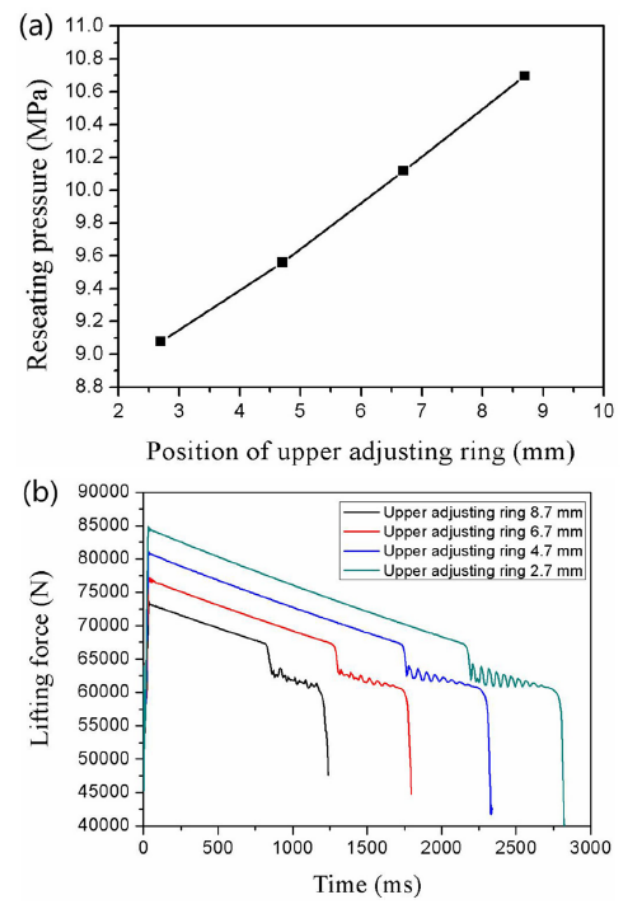

Fig. 12. Reseating pressure as a function of the position of upper adjusting ring (a) and fluid force acting on disk in the $y$-direction (b). ( $k_{\text {spring }}=743 \mathrm{Nmm} \_1$; throat size of $57.8 \mathrm{~mm}$ in diameter; $h_{1}=2.2 \mathrm{~mm}$; dry saturated steam).

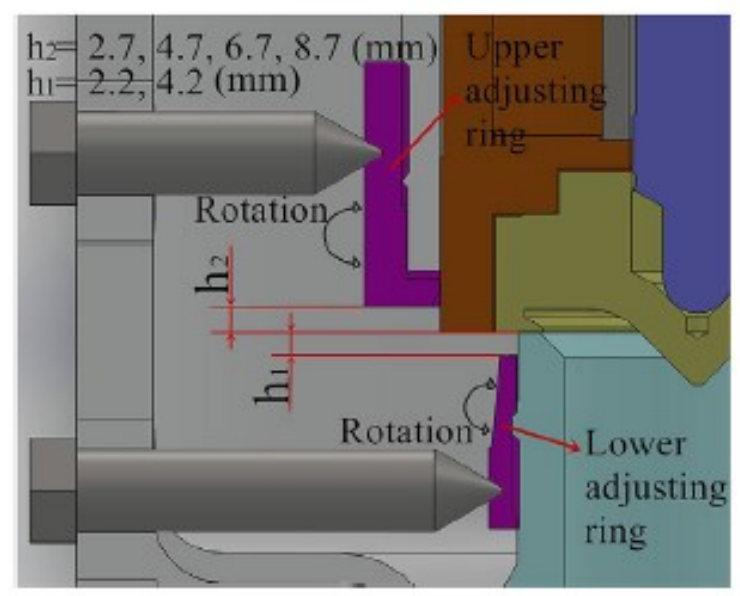

Fig. 13. Comparison of adjusting ring positions

The blowdown is accordingly adjusted from $25.720 \%$ to $12.480 \%$. This tendency is attributed to the linear increase in the lifting force on the disk during the DWPRV's opening, as demonstrated in Fig. 12(b). Fig. 14 demonstrates the pressure contours and the velocity vector diagram in the DWPRV seat region with two 
different positions of the upper adjusting ring. When $\mathrm{h}_{2}=2.7 \mathrm{~mm}$, both the steam pressure along the disk wall and the velocity along the $y$ axis at the gap between the upper and lower adjusting rings are higher than those of $h_{2}=8.7 \mathrm{~mm}$, thus leading to the larger lifting force for the case of $h_{2}=2.7 \mathrm{~mm}$ because the lifting force is the sum of local pressure and shear force. In contrast to the upper adjusting ring, the lower adjusting ring has a weak effect on the reseating pressure. Given $h_{2}=8.7 \mathrm{~mm}$, the reseating pressure of the DWPRV slightly decreases from 10.695 to $10.672 \mathrm{MPa}$ with the rise in $\mathrm{h}_{1}$ from 2.2 to $4.2 \mathrm{~mm}$. The blowdown increases from $12.480 \%$ to $12.668 \%$ accordingly. For the DWPRV, the upper adjusting ring alters the geometry of the flow field and the direction of fluid flow significantly. In contrast, the lower adjusting ring only alters the size of the channel between the disk and lower adjusting ring. The change in the direction of fluid flow inside the channel is negligible. Compared with the lower adjusting ring, the upper adjusting ring exhibits a high amount of change in the lifting force due to the alteration in the fluid flow direction. Therefore, the upper adjusting ring plays a more important role in adjusting blowdown than the lower adjusting ring. It should be noted that this tendency is related to this specific PRV geometry and the validation for alternative designs of HTHP PRVs needs further studies.
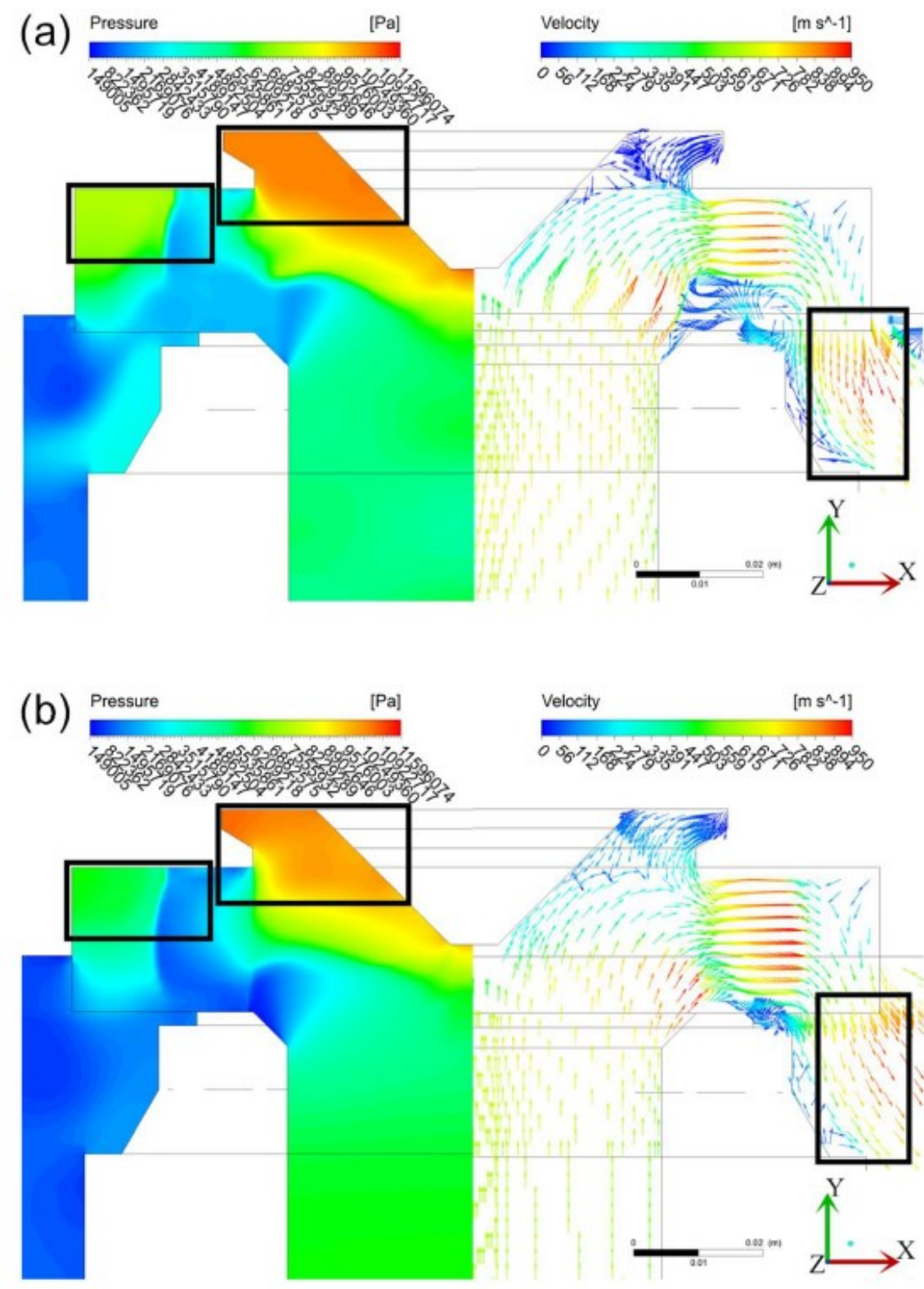

Fig. 14. Pressure contours and the velocity vector diagram of the DWPRV with discharge time ((a) $t=100 \mathrm{~ms}$, lift $=22.5 \mathrm{~mm} ; h_{1}=2.2 \mathrm{~mm} ; h_{2}=2.7 \mathrm{~mm}$; dry saturated steam. (b) $t=100 \mathrm{~ms}$, lift $=22.5 \mathrm{~mm} ; h_{1}=2.2 \mathrm{~mm} ; h_{2}=8.7$ $\mathrm{mm}$; dry saturated steam). 


\subsection{Effect of the rated lift}

For the design of a HTHP PRV, the input data are set pressure,reseating pressure and rated flow capacity. The throat diameter can be firstly determined in accordance with API Standard 520. Then, the rated lift (lift rated) is usually calculated by $0.25-0.35$ times the diameter of throat. The value of $0.25-0.35$ suggests that the ratio of curtain area to throat area exceeds 1. However, for the DWPRV, the curtain area should exceed the value of 1.18 times the throat area (the corresponding ratio of lift rated to the diameter of throat is 0.295 ) which guarantees the maximum flow rate can be achieved (see Fig. 11). That is, the usually used value of $0.25-0.35$ is not applicable to DWPRV. The maximum stiffness $\left(\mathrm{k}_{\max }\right)$ of the spring can be calculated in accordance with Eq. (10) (Kondratyeva, 1976).

$$
k_{\max }=0.9 \frac{F_{\text {flow,rated lift }}-p_{\text {set }} \cdot \frac{\pi}{4} \cdot D_{\mathrm{m}}^{2}}{\text { lift }_{\text {rated }}}
$$

where $F_{\text {flow, }}$ rated lift is the lifting force when the PRV reaches the rated lift; pset is the set pressure; $D_{m}$ is the average diameter of the sealing face. The effect of the rated lift on the performance of the DWPRV was investigated with various rated lift values of 17.5 and $20.5 \mathrm{~mm}$ corresponding to the ratios of rated lift to throat diameter of 0.3 and 0.35 , respectively. Accordingly, $\mathrm{k}_{\max }$ is calculated to be 1099 and $1004 \mathrm{~N} \mathrm{~mm}^{-1}$, respectively, according to Eq. (10).
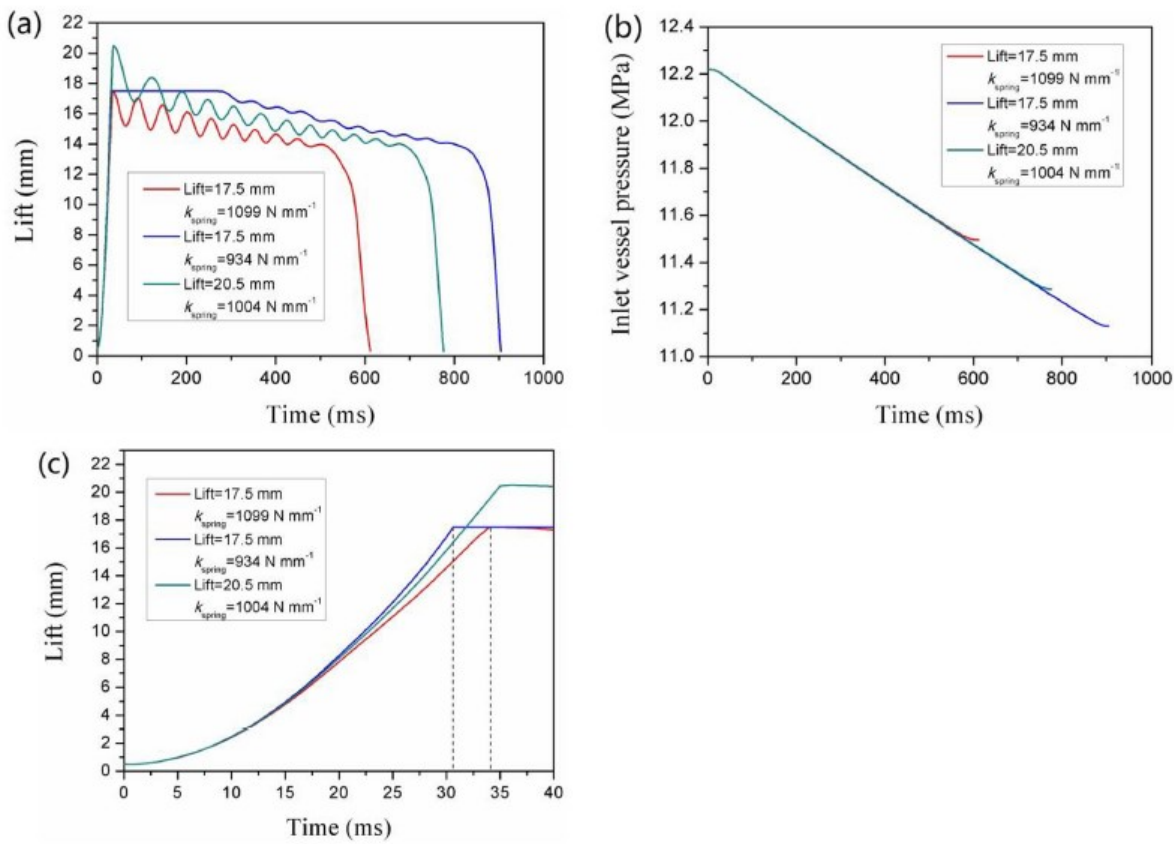

Fig. 15. The lift (a) and inlet vessel pressure (b) as a function of discharge time of the DWPRV; the lift as a function of discharge time of the DWPRV in the first $40 \mathrm{~s}$ (c). (throat size of $57.8 \mathrm{~mm}$ in diameter; $h_{1}=2.2 \mathrm{~mm} ; h_{2}=8.7$ $\mathrm{mm}$; dry saturated steam).

As demonstrated in Fig. 15(a), for the cases of the rated lifts of 17.5 and $20.5 \mathrm{~mm}$, fluttering can be observed with a quick reseating. The blowdown values for lift rated $=17.5$ and $20.5 \mathrm{~mm}$ are $5.92 \%$ and $7.64 \%$, respectively. For HTHP PRVs, the blowdown is usually in the range of 2-7.5\% according to API Standard 520. Given that the actual stiffness of the spring is lower than $\mathrm{k}_{\max }$, the actual blowdown for the DWPRV with the rated lift of 20.5 $\mathrm{mm}$ is higher than $7.64 \%$. Although the position of the upper adjusting ring can be changed to decrease the blowdown so that the higher limit value of $7.5 \%$ required by API Standard 520 can be met for a Rated Lift $=20.5$ $\mathrm{mm}$, the lower rated lift of $17.5 \mathrm{~mm}$ than $20.5 \mathrm{~mm}$ suggests a smaller PRV volume and consequently lower fabrication cost. For the rated lifts of $17.5 \mathrm{~mm}$, the effect of the spring stiffness on the performance of the DWPRV was studied. The spring stiffness decreases from a $k_{\max }$ of 1099 to $934 \mathrm{~N} \mathrm{~mm}^{-1}$ (85\% of $\mathrm{k}_{\max }$ ) and the deformation of the spring at the set pressure was adjusted accordingly to meet Eq. (7). As shown in Fig. 15(b), 
the reseating time increases from 612 to $904 \mathrm{~ms}$ and the reseating pressure decreases from 11.50 to $11.13 \mathrm{MPa}$. Accordingly, the popping time decreases from 34 to $31 \mathrm{~ms}$ (see Fig. 15(c)). Therefore, the decrease in the spring stiffness effectively reduces the reseating pressure and exhibits a slight influence on the popping time.

\section{Conclusion}

This study shows that the dynamics of a safety valve during opening and closing can be effectively simulated using CFD techniques by combination of DDM and GPM methods. It is confirmed that the use of CFD simulation can improve the design and settings of a PRV in a highly energetic service that is difficult to test due to safety reasons. CFD simulations can increase safety by reducing the amounts of bench testing needed to set the adjusting rings. For dangerous cases such as HTHP steam, this is critical to ensure safety. A comparison with experimental data shows that the model can predict accurately and in detail the multi-dimensional aspects of the flow and disk motion. However, accurate determination of the damping caused by the friction between the disk holder and the disk guide is necessary to predict fluttering of the disk. Fortunately for the conditions examined, fluttering and its associated damping exhibit only slight influences on the blowdown. A general investigation of the valve operating characteristics reveals that the maximum mass flow rate occurs at the ratio (curtain area to throat area) of 1.18 for the DWPRV. The reseating pressure of the DWPRV is overestimated if compressed air is used as an alternative. The degree of superheat ranging from $0 \mathrm{C}$ to $100 \mathrm{C}$ has a negligible effect on the dynamic performance of DWPRV regardless of the changes in the material mechanical properties with operating temperatures. A roughly linear increase in the reseating pressure can be observed for a DWPRV with the rise in $h_{2}$, the upper adjusting ring position. In contrast, the reseating pressure slightly decreases with the rise in h1, the lower adjusting ring position. This difference is because the upper adjusting ring can significantly change the steam lifting force by an obvious alteration in the fluid flow direction. For the ratios of rated lift to throat diameter equal to 0.3 and 0.35 , the DWPRV exhibits the higher blowdown for the ratio of 0.35 . The decrease in the spring stiffness effectively reduces the reseating pressure and exhibits a slight influence on the popping time.

\section{Acknowledgements}

This study was financially supported by the China Natural Science Foundation (Contract No. 21176069, 21476073) and the Fundamental Research Funds for the Central Universities (WG1213011).

\section{References}

Aldeeb, A.A., Darby, R., Arndt, S., 2014. The dynamic response of pressure relief valves in vapor or gas service. Part II: experimental investigation [J]. J. Loss Prev. Process Industries 31, 127-132. ANSYS, Inc, 2011. ANSYS CFX Reference Guide for Release 14.0. ANSYS, Inc.

Betts, P.L., Francis, J., 1997. Pressures beneath the disc of a compensated pressure relief valve for gas/vapour service [J]. Proc. Institution Mech. Eng. Part E J. Process Mech. Eng. 211, 285-289.

Beune, A., Kuerten, J.G.M., van Heumen, M.P.C., 2012. CFD analysis with fluid structure interaction of opening high-pressure safety valves [J]. Comput. Fluids 64, 108-116.

Carneiro, L.M., Pires, L.F.G., Cruz, M.D.S., Azevedo, L.F.A., 2012. Dynamic behavior of spring-loaded pressure relief valve: numerical and experimental Analysis[C]. 2012 9th international pipeline conference. Am. Soc. Mech. Eng. 553-561.

Darby, R., 2013. The dynamic response of pressure relief valves in vapor or gas service, part I: mathematical model [J]. J. Loss Prev. Process Industries 26,1262-1268.

Darby, R., Aldeeb, A.A., 2014. The dynamic response of pressure relief valves in vapor or gas service. Part III: model validation [J]. J. Loss Prev. Process Industries 31, 133-141.

Dempster, W., Lee, C.K., Deans, J., 2006. Prediction of the flow and force characteristics of safety relief valves [C]. In: ASME 2006 Pressure Vessels and Piping/ICPVT-11 Conference. American Society of Mechanical Engineers, pp. 93-99. 
Francis, J., Betts, P.L., 1997. Modelling incompressible flow in a pressure relief valve [J]. Proc. Institution Mech. Eng. Part E J. Process Mech. Eng. 211, 83-93.

Hos, C.J., Champneys, A.R., Paul, K., McNeely, M., 2014. Dynamic behavior of direct spring loaded pressure relief valves in gas service: model development, measurements and instability mechanisms [J]. J. Loss Prev. Process Industries 31,70-81.

Kim, H.D., Lee, J.H., Park, K.A., 2006. A study of the gas flow through a LNG safety valve [J]. J. Therm. Sci. 15, 355360.

Kondratyeva, T.F., 1976. Safety Valve [M]. Mechanical Engineering, Leningrad department, Leningrad (in Russian).

Kourakos, V., Rambaud, P., Buchlin, J.M., Chabane, S., 2013. Flow force in a safety relief valve under incompressible, compressible, and two-phase flow conditions (PVP-2011-57896) [J]. J. Press. Vessel Technol. 135, 244-252.

Moncalvo, D., Friedel, L., J€orgensen, B., H€ohne, T., 2009. Sizing of safety valves using ANSYS CFX-Flo ${ }^{\circledR}[\mathrm{J}]$. Chem. Eng. Technol. 32, 247-251.

Narabayashi, T., Nagasaka, H., Niwano, M., Ohtsuki, Y., 1986. Safety relief valve performance for two-phase flow[J]. J. Nucl. Sci. Technol. 23, 197-213.

Ray, A., 1978. Dynamic modeling and simulation of a relief valve [J]. Simulation 31, 167-172.

Rogovin, M., 1979. Three Mile Island: A report to the commissioners and to the public [R]. Nuclear Regulatory Commission, Washington, DC (USA).

Sallet, D.W., 1984. Thermal hydraulics of valves for nuclear applications [J]. Nucl. Sci.Eng. 88, 220-244.

Sallet, D.W., 1991. Critical mass flow rates through pressure relief valves [J]. Heat Mass Transf. 26, 315-321.

Sallet, D.W., Nastoll, W., Knight, R.W., Palmer, M.E., Singh, A., 1980. Experimental 